Tadeja ZUPANČIČ

Tomaž NOVLJAN

Matevž JUVANČIČ

Špela VEROVŠEK

Maruška ŠUBIC KOVAČ

Andreja ISTENIČ STARČIČ

Matija SVETINA

\title{
The concretization of the term sustainable spa- tial development for the assessment of child and juvenile awareness
}

The following article is targeted at the comprehensive co-shaping of the conditions required for the active education on the effective and concrete contributions to sustainable development, with the emphasis based on the built environment or architecture. It defines the role of education on the built environment or architecture within the concept of sustainable development, determines the grounds for adjusting the methods of delivering architectural contents and defines the educational contents along with their presentations with regards to the developmental abilities of the public, which is targeted. It presents the deliberation on objectifying the term sustainable spatial development, for the assessment of child and juvenile awareness of "sustainable architecture" topics as well as determining childcare workers and teachers adequate qualifications to provide the knowledge in the field of the built environment, in relation to sustainable environment. Concretisation signifies the selection and visualisation of actual topical occurrences in physical space for a specific targeted public (the article provides representative models). It also contributes to the development of "cultural" dimension of spatial development sustainability. The efforts made to strive towards the lifelong learning of architecture and its influence on our everyday lives and our future.

Key words: cultural dimensions of spatial sustainability, architecture, built environment, lifelong learning, children and juveniles 


\section{Introduction}

The article provides the results of the first milestone of the research study, titled "Education on the built environment for sustainable development", which is currently being carried out within the framework of the national Targeted research programme Slovenian competitiveness 2006-2013. The subject of study is the visual concretization of the concept of cultural sustainability of spatial development for a specific targeted public.

Whilst composing the article, a selection of topical concrete occurrences in physical space with respect to the cultural sustainability of development was made, which includes the survey for primary and secondary school pupils. The survey is to be commented on by teachers as well. The second part of the research comprises of the specific experiment, which will be performed at model primary schools and grammar schools in Slovenia (in execution during the article preparation), and the assessment of child and juvenile awareness (as well as their teachers), with respect to the comprehension of the concept of cultural sustainability of spatial development.

The basic starting point of the entire project is to support the government and other significant active players in Slovenia, who contribute to the designing and exercising the political manoeuvrings in achieving the intergenerational and sustainable development that implements the principles of sustainability in all facets of development. The society of knowledge, which with sustainable "sensitivity" manages its physical-spatial conditions for existence and cultural progress, and by doing so builds its international competitiveness, is formulated by the synergy among the basis of "establishment and development of cultural identity" and "integration of measures needed to be taken in order to achieve sustainable development". However, "the country's interest" regarding the establishment of the principles of sustainable development, as defined by the planning documents, has not yet reached the level of implementation. The problem arises due to the one-way processes "top down", whereas sustainable orientation requires balanced processes "from top" as well as "bottom up". The first question is how to develop the concept of sustainability as the starting point of education.

For the benefit of the development of cultural identity, special attention is paid to the "cultural" dimension of spatial development sustainability. In this context, architecture is regarded as the essential part of culture, which represents the spatial conditions as well as traces of cultural activity (cultural environment - architecture space). European associations have already founded that not only physical health and proper relations among people, but also public interest characterise the best possible living environment. Concerning European directives for job qualifications in the field of architecture, "architectural modelling, buildings' quality and their consistency with the natural and urban region" are matters of "public interest" of all European countries.

Mutual acknowledgement of qualifications must therefore be based on the measures of quality and quantity with a guarantee that persons with recognised qualifications are capable of understanding and fulfilling the needs of individuals, social groups and authority bodies as far as spatial planning, modelling, organisation and realisation of structures, preservation and exploitation of architectural heritage and protection of the natural balance are concerned (Internet 1).

According to architecture as a generalised profession, the built environment is treated in its widest sense, in its relationship to the natural and as such, it is regarded as a cultural environment. The existing problem of defining the relevant contents indicates the need for interpretation of sustainable development, as public interest in cases where public interest is most threatened and instantaneous interventions are most urgent. One such case is public space, for which in Slovenia the conditions for the proper protection have not been yet established. Numerous cases in Slovenian spaces prove that the inadequate conduct of one man alone can offset the positive efforts made by the wider public. Hence the question, how to concretise the concept of cultural sustainability of spatial development?

The project's main subject matter is the issues of general education. The emphasis is made on primary and general secondary school education. The primary and secondary school curricula analysis conducted so far mainly deals with the abstract, the conceptual perspective of sustainable development (Internet 2). Although the experience approach is present, its fundamental value is neglected in general education. The experience approach, the closest to the younger generation, offers the highest level of efficiency in mediating ideas (Zupančič and Juvančič 2003). Children and juveniles are first familiarised with the world through experience, which they later conceptualise. This results in the need to become familiar with sustainable principles through experience, from their rooms, homes, neighbourhoods, streets, settlements ... So, one of the basic problems regarding the discussed topic from a scientificeducational perspective is the approach itself.

The most important question arising; is how to achieve a turning point in the approach and allow for a complementary path of both perspectives, with priority given to the experience approach at the early stages of education. To the question on "concretising" of the cultural sustainability, the following question could be added: can the concept of cultural susta- 
inability be concretised to such an extent that the required turning point in the approach to the general education on sustainable development will be achieved? What needs to be considered when choosing and possibly establishing new ways of mediation of architectural contents with respect to children and juveniles?

The aim of the project is to contribute to a comprehensive co-shaping of conditions for a more effective form of education on efficient, concrete inputs for sustainable development, with an emphasis on the built environment or architecture.

Throughout the project inductive and deductive approaches are intertwined. The problems in the task are observed in an interdisciplinary fashion through the perspectives of important studies which are involved (or should be involved) in the educational process of sustainable development of the built environment, in its connection to architecture, urban planning, developmental psychology, pedagogy etc. The prevailing method is the descriptive method, complemented with the empirical approach (including statistical data processing and adjustment of currently used method - during the assessment of pupils in the continuation of the research).

In the article at hand there are three objectives/results

1. To determine the role of education on the built environment within the concept of sustainable development

2. To lay the groundwork for the modifications of the methods of mediation of architectural contents

3. To determine the educational contents and their presentations with regard to the developmental abilities of the targeted public, namely for:

- assessing the level of child and juvenile awareness of "substantial architecture" themes

- determining the qualifications of childcare workers and teachers for mediation of knowledge in the field of the built environment, in correlation to sustainable development.

The article presents a transparent part of the above mentioned research: the overview of different perspectives, which are vital for the preparation of the experimental phase. The perspective of the meaning (Why does the educational basis need to be built on the concept of sustainable spatial development?) is complemented with the contents perspective (What to concretise when we have in mind the cultural dimension of sustainable spatial development, especially the concept of living culture?). The perspective of manner (How to concretise the covered concepts?) is however developed from the point of view of theory of presentation (as a part of architectural theory). With reference to the targeted public there are two additional aspects covered; the perspective of developmental psychology (children and juveniles) and didactic perspective (teachers).

At the end of the overview appears the synthetic concretisation of the concept of cultural sustainability of spatial development: the selection and visualisation of topical, concrete occurrences in space for selected targeted public, in the form of a questionnaire. This article presents representative models of this synthesis.

The titles of chapters in the article are derived from project's objectives:

- Development of the concept of sustainable development as the grounds for education (objective 1).

- Objectifying the concept of the cultural sustainability of spatial development (objective 1).

- Selection of concretisation (objective 2).

- Visualisation of living culture (objectives 2 and 3).

- Children's understanding of abstract concepts (objective 3).

- Teacher's role in upbringing and education on sustainable development (objective 3).

- Concretisation: questionnaire for children and juveniles (objective 3).

The final chapter summarizes the findings and indicates the following work.

\section{Development of the concept of sustainable development as the grounds for education}

The future of mankind and quality of life depends on man's ability to achieve a sustainable balance with the global environment. Balancing man's needs for retaining the natural and built environment, at present and in the future, is connected to the concept of sustainable balance, whereas development is connected to the concept of sustainable development. Although the idea of such development is not entirely new, the principles of sustainable development, which were adopted in 1992 in Rio de Janeiro in Agenda 21 (Internet 3), represent an important milestone in the perception of human development and at the same time introduce the basis for several strategic documents on a global, European and national level. In the 90s, sustainable development became the guiding principle of EU environmental politics.

"Sustainable development" is from the perspective of the concept, is in general regarded as development which meets the requirements of today's generations without threatening the development of future generations (Internet 3). Plut (2007) 
warns that the Slovene term "trajnostni razvoj" may not be the best translation for sustainable development. Slovar slovenskega knjižnega jezika (The dictionary of Slovene literary language) defines the term "trajnost" as "a characteristic of something regarding to the fact of how long it can exist or be useful" (DZS, 2002). According to Plut $(2005,2007)$ the term "trajnostnost" emphasises the goal, tendency for lasting or sustainable maintenance of natural (environmental) capital and simultaneously long-term (lasting) designed economy and the entire society. The term is useful if we want to stress the wider concerns with respect to the improvement of quality of life issues, equality of people at present and also into the future, nevertheless within the scope of the environment's and nature's abilities. In his opinion the term "sonaraven" (sustainable) is narrower in its meaning and relates to the implementation of principles of environmental and nature protection, therefore environmental sustainability. Whereas, on the one hand the term "trajnosten" determines and emphasises the time horizon, on the other hand, the term "sonaraven" determines the manner of operation and management, which is coherent with nature itself.

In this article we have restricted ourselves to the built environment, however only in its relationship to the natural, with a touch of culture. Environment in its wider sense, is determined as the natural environment, anthropogenically redesigned natural environment (cultivated areas, cultivated forests, controlled water conditions) and mostly anthropogenic or technogenical environment (settlements, mostly cities, industrial and traffic installations (Ilešič, 1979). The latter has been in modern era referred to as the built environment. According to Evroterm (Internet 4) the built environment ("grajeno okolje", "gebaute Umwelt") is the part of nature created or managed by man, for example buildings, larger structures, roads, bridges as well as smaller structures such as traffic lights, phone booths and bollards. In this article, sustainable development within the built environment is linked to its cultural component, its quality. That is to say the quality of the built environment significantly contributes to a balanced sustainable development.

Education on sustainable development within built environment is a significant factor for the implementation of the principles of sustainable development. The majority of strategic documents on sustainable development emphasise the proactive politics of education and training of children and juveniles in the field of sustainable development (Internet 5; Internet 6). Agenda 21 (Internet 3) claims that environmental education develops values, conduct manners and responsibilities required for the creation of a sustainable balanced future. The thematic strategy insinuates that local bodies should encourage, through the use of sustainable building methods in order to raise public awareness. We believe that education on the built environment plays an important role in the field of sustainable development not just in the case of people who are trained for participation in decision-making on problems of the environment and its development. The individual in question is a person capable of critical judgement of man's influence on the built environment, aware of environmental advantages and problems, and at the same time a person possessing the knowledge and skills to adequately participate in the care of the built environment. All in all, an individual who will through their participation, enable sustainable development to solve existing problems and prevent the occurrence of new ones.

\section{Objectifying the concept of cultural sustainability of spatial development}

What is the purpose of mediating the architectural-urbanistic contents and ethics of intervention into space toward the general public and in particular toward the younger generations? The essential ingredient for achieving cultural sustainability of spatial development is formal rules (laws, regulations, spatial planning acts etc.), which enable public co-operation in the planning processes, prescribe, restrict and apply sanctions for actions in space, and at the same time actively educate all the players (also potential ones) about architecture and the ethics of operations in space. The enhancement of the learning process and familiarisation with the world, throughout all the life stages of an individual coincides with the broadened view of the profession on the relationship between space-user and spatial problems which professionals face in different life circumstances and on different levels (age, maturity, educational, interest). Evidently, the adjusted levels of education takes precedence over education in the sense of altering the already established system of values, views and beliefs of individual target groups of the general public. The advantage of an early and gradual learning process can be seen in the mediating of such contents in good time or even before that stage of individual's active intervention into space.

A common user of space experiences difficulty in perceiving the significance of cultural sustainability. If the majority of the general public consider the words "environmental" or "sustainable" only from the natural perspective of these two terms, as just mutual relationships between man and nature, this mental concept is lacking and what is just as essential is - cultural component. It is especially in time when the borderlines between the cultural and natural landscape keeps disappearing, that cultural and natural components of sustainable environment cannot be treated separately any longer. The belief is shared by some authors, who claim that sustainable development is not only about tangible, physical concepts, but it also "sustainably" 
includes the social, aesthetic and economic perspectives in correlation to an individual's and a society's well-being. Despite the variety of definitions and perspectives of the wholesome spectre of the sustainable problematic, most authors agree that the shaping of the living environment (in its widest sense), which includes architecture, urbanism and other studies dealing with planning, construction and intervention into space, have a significant effect on the quality of the environment and on living in general (positive and negative). According to Hagan (2001), architecture has always taken an ambivalent attitude towards the natural and the cultural, which with the pursuit of sustainable development only keeps magnifying.

How can the concept of spatial sustainability be communicated to users and the younger generations, who take part in the process of education? The entire sustainability problematic in the field of shaping space, can easily be centralised around the concept of living (for each individual of existential significance), which is most frequently related to residences - architecture, their placement in space and their mutual relationship - urbanism, spatial planning. A wider meaning of the term living, which comprises of the majority of man's activities, from his residence and close surroundings, to transport, communication, work and the working environment and last but not the least leisure time activities. Most of the enumerated activities are have at least an indirect connection with shaping buildings and space. To facilitate an individual's perception and understanding of global dimensions, inconceivable measures, quantities and masses, the view of such perspectives is diverted down to an individual's experiences and their everyday activities.

On the first level, it is sensible to concretise the mediation of cultural sustainability of spatial development with regard to the concept of local: "All sustainability is local" (McDonough, 1998: 49), since individuals always derive from and operate locally, contemplating; here I am, surrounded by this natural and cultural environment and I move within these social, philosophical and economic circles. The already mentioned centralisation of the concept of sustainability around living diverts the intervention into space by individual players, which allows individuals to recognise themselves in each of them and more easily visualise and get accustomed to them.

When delivering the environmental problematic and the problematic of space intervention, it is necessary to equally highlight all three columns of sustainable development (the natural, social and economic) and the coherences amongst the factors which build the environment. By doing this, it is important to educate about those processes and phenomena, which are more difficult to measure and whose consequences are realised with a time delay or are less present in people's consciousness or are due to their special local features, more difficult to be generalised. While respecting natural resources, respect of cultural factors needs to be considered as well: consideration of individuals and their needs (importance of well-based concepts), of existing quality spatial groups in space, socioeconomic conditions, integration of all groups and individuals into the decision-making and formation of space as well as the economic tendencies for sustainable activity (short-term and long-term contributions).

From the point of view of sustainable development, a lack of intervention and materialisation can in certain cases be the best "interventions", even better than building, changing and remodelling. Deliberation and a sensible abstinence during procedures therefore accounts for values beyond all measures of space intervention. Among the basic contents, are those elements which are worth presenting during the process of general education and are the contents connected to building and with intervention upon the built environment.

\section{Selection of concretisation}

The chapter regarding the basics for adjusting the manners of mediation of architectural contents focuses our thoughts to the question: Who mediates what, to whom, how and why so?

Assuming that "who" is an architect and "what" the architectural contents, hence the thing which shapes quality architecture as one of the basic conditions of the cultural survival of the society which participates in the creation of the architecture. Let us consider as an example the experiment of mediation of the concept of architectural quality, and it goes without saying that us architects, make use of visual communication. The concept can be demonstrated with a symbol we use to evoke the reader's imagination and his/her concrete associations or with an example which absorbs an individual into a concrete perception about something, he/she may not agree with at all. We might choose the case of architecture with respect as to whose quality a certain number of people agree, or we can emphasise the case of people who feel good in a particular space and show them to the individual. Nevertheless, the concept of architectural quality is more "concrete" or at least "narrower" than the concept of sustainable development. However, both are less complex than for example the concept of "development". On the other hand, the concept of development might be easier to visualise than the concept of sustainable development; in fact the concept of architecture in general would probably be much easier to perceive than the concept of architectural quality. But is it really so? Architecture can in general be an activity or no less than a trace of an activity, but the concept of "architectural quality" can be at least on the face of it be regarded as architectural space. An important basis for adjusting the manners 
of communication are, abstractness, complexity and the hoe the message is presented.

The contents of the messages we would like to convey, differ with regards to how we ourselves, understand the problematic under consideration and how it is perceived by our targeted public. In the given example, we have on the one hand an interdisciplinary project group and on the other hand children and juveniles and their teachers. The differences in the question are those regarding the "sustainable awareness" of the targeted public and those between a mediator, and the selected targeted public. These differences depend on development, education etc., and are evident in system of values, and they affect the objectives in co-shaping the space. The question is how different players within the communication process are capable of visual mediation of their mental images of space in order to firstly recognise and then exceed the differences between the systems of values and objectives in a mutual dialogue. An important role is assigned to developmental, educational, etc. conditioned manner of thinking (ability of abstract thinking). The manner of communication must therefore reflect upon "sustainable" awareness, abstractness of thinking and visual competence of the targeted public.

What are the chances regarding the manners of communication anyway? The approach depends on "the perception of the world" (Bosselman, 1997: 2-19), which may be as the message itself is either abstract or concrete. The concrete approach is directly derived from experience, whereas the abstract approach, indirectly. The examples of the former are: a perspective drawing, photography with realistic distances and angles of the optical lens, the digital environment, which is dependent on alterations of the observation point and takes a man as concrete criteria. The examples of the latter are: aerial photo shots, maps of the city, plans etc., for which abstract criteria can be determined. In principle, the selection of one of the above mentioned approaches and their polar combination or the choice of intermediate options does not depend on the choice of presentation medium. However, the practice brings forth the findings that for certain messages some media works better than for others, they can be more efficient, realistic etc. (Juvančič and Zupančič, 2008). All in all, abstractness and the media of presentation are vital.

In the following chapter, "what" signifies the living culture, "how" stands for visualisation, which as regards "to whom" we are visualising is not a subject to visual arts - aesthetic criteria, although the "who" visualising is an architect. The selection of elemental combinations may signify an attitude towards living culture, even in the case of consciously neglecting the visual arts.

\section{Visualisation of living culture}

One of the primary elements of the sustainability of development of an individual or a group of people is the culture of living. The term culture is a "partial resultant of forces" of achievements or values of human society and an individual's participation and creation. By adding the terms such as to reside, inhabit, live, exist, be, the final result totals in actually everything that a man does in his life, which means that the culture level of an individual or a group of people manifests itself in the most intimate way of being, the by products of it, being its visible consequences. A lower level of a human's living culture results in a contrary relationship between the organisation of private living and a man's attitude to semipublic and public living, beginning with the attitude toward common elements - green areas, still traffic, rubbish. The key historical starting point of the culture of living most certainly lies in geographical location, which has always been closely connected with climatic effects. The culture of living in northern latitudes has unquestionably always differed from the culture of living in for example the Mediterranean. Owing to technological advances and the development of all kinds of communications and the globalisation process, the characteristics of various living cultures have approached one another to a large extent. So, today's differences in living culture occur due to the economic and political development of a certain area, which can be seen in a more and more wholesome and universal visual expression of architecture, which increasingly occupies our modes of perception. Namely, three quarters of a man's perception of all environmental stimuli is achieved through visual perception. With adequate lighting, an observer recognises structure, texture, colour, all being interdependent. Interdependence is conditional upon the relationship between the observer and what is being observed or the distance between the observer and the object itself. Space is perceived through an arrangement of objects. The arrangement of objects is perceived through distance, and distance has direction and anti-direction. Therefore, it does not matter in which direction the object is being observed (Bonča, 1990). When determining the level of living culture, a visual presentation or illustration of individual spatial elements or clusters, is the dominant way of mediating information about space. At the same time, it allows an insight into a human's ability with regard to perception and the understanding of space surrounding him. In all this, age (experience) plays a very important role. The rules of visual expression in composition of elements, shapes and colours are upgraded in the form of visual emphasis of individual elements and clusters. These may be bold lines - outlines, contrasting colour, oversized and an excessive number of elements, abstraction, deliberately highlighted mistakes, distorted perspective of space geometry etc. The nature of the individual question or cluster of questions that research focuses on is herein conside- 
red. Size, shape and the number of elements on the house or premises are hypothetical and serve merely as a set of options available at filling in the questionnaire (Figure 1).

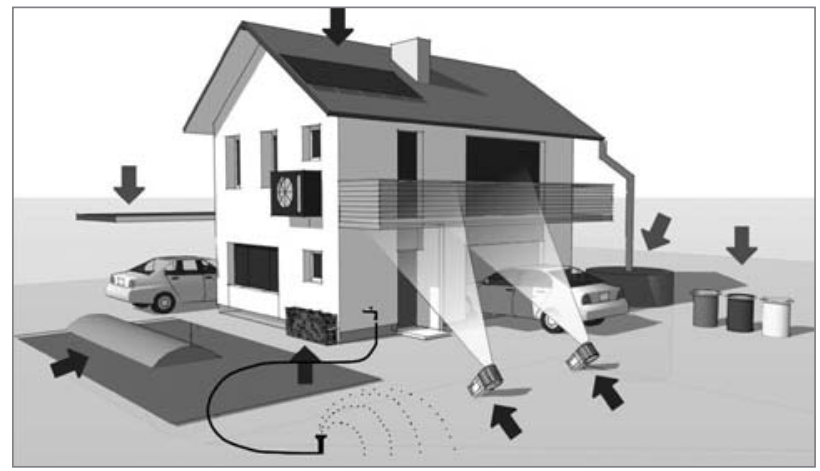

Figure 1: Instruction for a pupil: "Choose environmentally friendly elements and systems". Adjustment for the first three grades in a primary school: "In the picture, circle everything that helps preserve nature." (Illustrations: Tomaž Novljan).

\section{Children's understanding of abstract concepts}

Developmental psychology studies consistently show that children's understanding of things and events, differs from those of adult's: understanding of events is connected to motivation, attention span, previous knowledge, abilities, views, personal characteristics, circumstantial and contextual factors, system of values and levels of development (Gray, 1999; Haberlandt, 1994; Siegler, Deloache and Eisenberg, 2003). Since we cannot provide the appropriate insights into all these factors, we are going to name only some of most important views of mental development, which are vital in understanding the concepts of space, and sustainable development with respect to children, especially the processes of internalisation and formalisation of thinking, and the development of concrete and abstract forms of deduction.

The concept of sustainable development includes various elements among which environmental, spatial, aesthetics, historical, geographic, social, cultural, logical and contextual are to be highlighted. An individuals understanding of a concept from only one or a limited number of elements means a normative variation of developmental psychology and is crucially linked to the specific understanding of the concepts, which are directly or indirectly connected to the concept of sustainable development. However, the data of studies carried out in developmental psychology from the previous decades consistently shows that different forms of formal-logical thinking, required for the insight into the mutual relationship between visual, spatial and contextual elements of concepts, develop only between the ages of eleven and twelve (Rice, 1998; Zupančič and Svetina, 2004) - meaning at the stage of adolescence. The development of formal logic is coherent with the development of abstract deduction and symbolic second order thinking. First order thinking relates to the development of operations between concepts and relations, which on a concrete level can only be hypothetical and inconceivable, while the second order is connected to the development of logical operations amongst concepts and images on different levels of abstractness, forming classifications, understanding of relationships within relations and development of meta-cognition. The development of all these abilities enables individuals to mentally overcome the limits of the concrete, physical reality and make deductions without concrete physical images, or so called meta-contextual thinking. Individuals becomes capable of complex forms of meta-cognition and develops an insight into the complexity of metaphors, symbols, relations among elements of mental concepts, which are necessary for the complex understanding of the term sustainable development.

In order to familiarise children and juveniles with the contents of the term sustainable development, these contents must be concretised and implemented into the environment of a child's experience, thereby considering the particularities of the context and the individual's developmental stage on a mental, motivational as well as on a social level.

\section{The role of the teacher in the process of upbringing and education for sustainable development}

Upbringing and education on sustainable development in the built environment indicate a noticeable intertwining of cognitive, emotional, aesthetic and behavioural ingredients. Learning the terms, natural laws and theories, coincides with learning views and values. Special attention is paid to a child's and a juvenile's experience of aesthetically encouraging sustainably oriented objects and materials and to the development of a relationship towards the built environment, which is being established within the concept of sustainable development. In the social-cultural environment with technological developments and the development of informational and communicational technologies, a child or a juvenile transcends between the home environment and other virtual and physical environments. Motivation and a readiness for learning are formed through a child's and juvenile's perception and their relationship in the environment, approach to learning, the connection between formal and informal learning and interests. The objectives of sustainable development aim at retaining identity, culture and the environment, perceiving and familiarising with the world as well as recognising its sustainable development (Salite, 2002). It is vital for individuals to be aware of their accomplishments 
in these conditions. A child's and juvenile's expectations, perception of oneself and one's accomplishments and goals that one has set, arise from the interaction with the environment on which they also exert an influence. Education on basic values, comprising the values concerning ones relationship and conduct within the built environment, sensitivity to aesthetics and the culture of living, begins at an early stage. An individual who is confronted with the problems of managing the environment at an early age identifies and personalises the value of caring for the environment and is far more likely to adequately treat the environment in the future, when that individual him/herself will in their professional as well as in their personal life contribute to the formation of the built environment.

In the field of education regarding sustainable development, attention should be drawn to a few didactic perspectives. Does the curricular system, while developing a sense of awareness for the built environment, support the sensual, mental and reflexive perception and use of visualisation strategies, and strategies of abstraction, imagination, action and interaction? Are the contents integrated on all areas at the appropriate level of intersubject integration, which ensures the foundations for a creative sustainable development in all disciplinary areas? Is inter-subject drafting of educational goals and contents encouraged and assured? Is the principle of authenticity regarding the contents and teaching methods adequately applied to the school curriculum in order to encourage problem based teaching, experimental learning and adventurous education, with problem analysis and experience? In order for education on development to achieve the goals on the recognition and value level, and have an effect on an individual's life style, sustainability should be treated in an interdisciplinary fashion from the first contact with the topic and a socio-cultural aspect should interlace with science, engineering, technology and environmental health.

Among the most essential characteristics a teacher should possess is the skill for developing an attitude, value, knowledge and experience needed for protection and improvement in the quality of life in the built environment and its sustainable development, whereas teacher's generic and subject-specific attributes should be an in-depth knowledge of the built environment as an integral part of man's environment and man's activity in it, and of the culture of living for the sake of a better quality of life and sustainable development.

\section{Concretisation: Survey for children and juveniles}

While becoming acquainted with the sustainable problematic in the built environment, the above mentioned principles were concretised in the form of concrete, illustrated questions. In this way we asked the future players in space what decisions they would make in the living conditions related to building and therefore also to sustainable spatial development. The questions were prepared in accordance with contextual sets, which beforehand had been determined in a transparent matrix, which included the backgrounds of particular sets, their importance for sustainable development and a content-related explanation and meaning of the questions. We made comparable variants of the questionnaire and so embraced three age/ developmental levels: the first; from the first to the third year of primary school, the second; from the fourth to the sixth year of primary school and the third group; from the seventh year of primary school to the fourth year of grammar school. The variants are derived from the same graphical basis, however, in some variants we adjusted the structure of the task (matching instead of ordering, colouring instead of circling etc.) and the phraseology in the tasks' texts (upper and lower case lettering). The difference between the first and the second level is mostly in the narrative of the question "Why?" which examines the reasons for choosing a particular answer (at the first level the answer was not expected). All questions are illustrated and mostly close-type questions. Open questions are the already mentioned questions "why" and those presuming the answers in the form of a graphical expression, with brief descriptions. The questionnaire consists of six upright $\mathrm{A} 4$ pages (20 questions).

While putting together this article, this survey is being held at selected schools: three primary schools and three grammar schools (the complete population of these schools app. 3,500 units). Since the research is still in progress, an evaluation of the results cannot yet be reported. The result of the project at the moment is the questionnaire and its preparation process.

The illustrated questions mainly deal with residences (Figure 2) and other objects (Figure 3), their positioning in space, formation, size and the respondents' attitudes towards built cultural heritage and free areas. The interviewed persons can choose amongst various ways of materialisation (different constructions, greening and preservation of lands not built on). We are also determining their attitude towards various everyday activities (traffic, shopping, free time), which contribute to the shaping of living space itself (Figure 4). With the last question we wanted to examine the attitude of the interviewed persons with respect to the local environment they are familiar with - for the common denominator of all interviewed persons from one institution, we chose the school's entrance for which the pupils had to find out what was missing, how they would change and supplement it. In this way we complemented the two variants of questions adapted to different levels with six more variants of questionnaires for each school $(2 \times 6=12$ variants of questionnaires). Due to the restricted space in the article we present you with only a selection of these questions. 

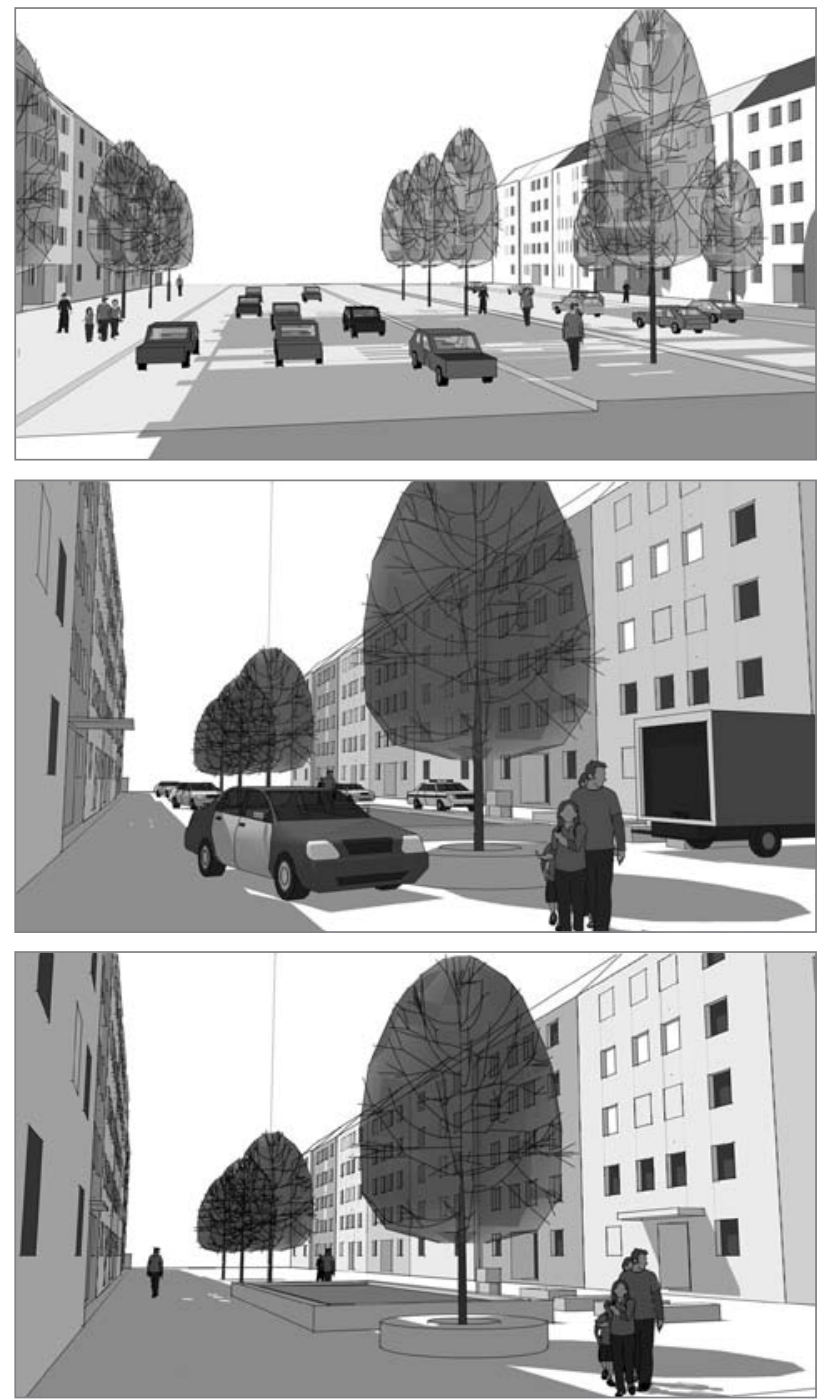

Figure 2: Question for a pupil: "In which street would you rather live? Why?" (Illustrations: Tomaž Novljan).

The covered survey is intended for teachers' remarks as well, since special questions were added for them too. The research done on Slovenian teachers covers the teacher's expectations, preparation and practice. It is aimed at an analysis of perception of knowledge, teaching and learning in the field of investigation. Special attention is paid to the analysis of the interaction between the teacher and the curriculum, in the school and the local environment and the teacher's interpretation of the contents and didactical design, which is reflected in establishing a learning environment. The overview of the predominant teaching and learning methods and strategies at the lectures on sustainable development, with special consideration with respect to the built environment and living culture, is examined from the aspect of the teacher's lesson planning and classroom performance. The process-product model for teaching (Brophy and Good, 1986) includes teaching factors but no links to teacher's lesson planning. In the analysis of the teacher's approaches to teaching sustainable development, the teacher's lesson plans
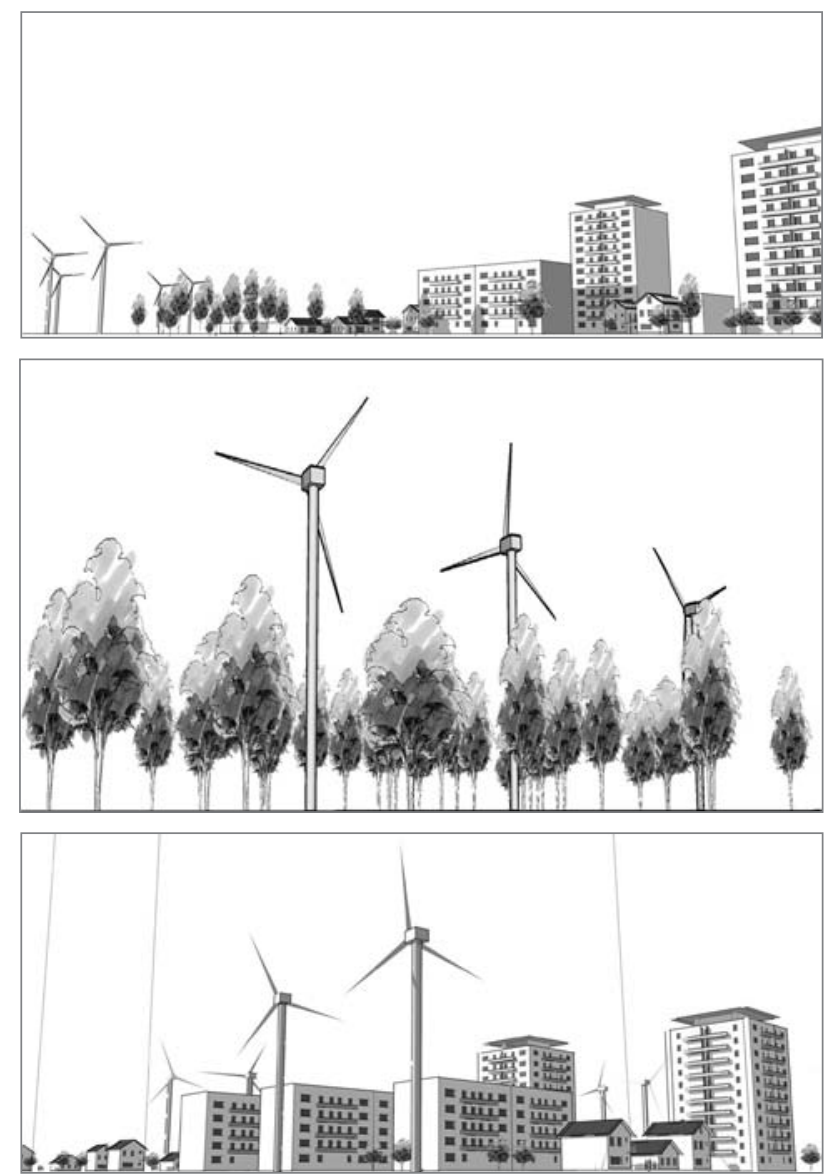

Figure 3: Question for a pupil: "Which environment do you find the most appropriate for weathervanes which generate electrical energy? Why?" The question was adjusted for the first two groups in primary schools: electrical energy - electricity (illustrations: Tomaž Novljan).
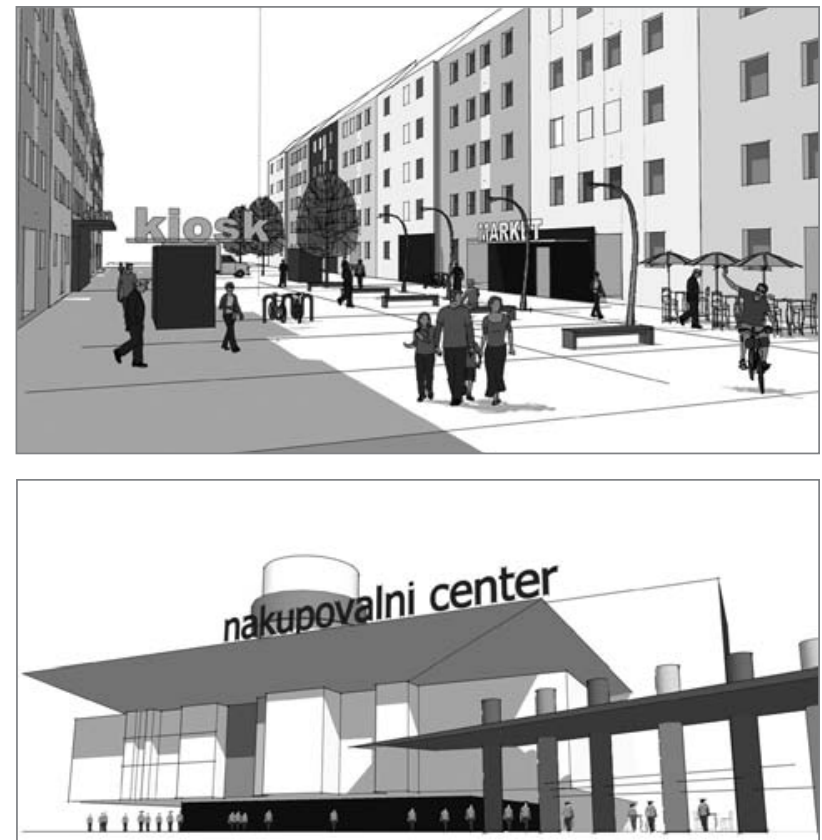

Figure 4: Question for a pupil:"Where would you rather go shopping? Why?" The question was adjusted for the first two groups in primary schools with addition: "with parents" (illustrations: Tomaž Novljan). 
for addressing "sustainable" topics is an important part of the analyse, since if a teacher's lecturing in the class was carried out on the basis of teaching methods and selected student's activities, most of these had been accepted in the phase of lesson planning (Berliner, 1988; Bromme, 1992) and not during classroom performance. A teacher's decision-making is based on goals, learning components, instructional methods and media and resources (Schulz, 1965). The analysis of the situation in the field of teaching and learning for sustainable development will cover the preparation and also the classroom performance, including the factors influencing the decision making on teaching actions and an evaluation of the lesson regarding the preparation and quality of processes and outcomes.

\section{Conclusion}

Sustainable development is a dynamic category, therefore concretisation of education on built environment should always be critically judged. This form of education can play an important role in the sustainable management of spatial development processes, if people receive the training in order to make long-term responsible decisions with regard to the concrete problems of the environment and its development.

It is in every country's interest, as a national interest to retain the quality of space, as quality creates competitiveness. Several European countries are already building their competitiveness on this recognition. Modest dimensions of a culturally and spatially sensitive country abound with possibilities; demand the highest level of awareness of the principles of sustainable development and of the potential, concrete, contributions to the selected development orientation process. The significance of architectural education in the context of achieving "cultural sustainability" of development is more than obvious.

However, declarative records of sustainable development offer merely an apparent solution to the question of important contents. It is only with determining of the mediation manner that the contents can be adequately concretised and effectively conveyed to the targeted public. Nevertheless, the contents must be adjusted to different levels of abilities in various forms of formal and informal learning.

While choosing and implementing new ways of conveying architectural contents to the public, the characteristics of contents' message, such as its abstractness, complexity and how it is perceived, must be taken into account. The differences between developmental, educational etc. characteristics of the mediator and the recipient of information: the awareness level regarding the selected topic, ability to perform abstract thinking and visual ability, (ability of visual communication) are of no less importance. Finally, the level of abstractness and the medium of presentation should be mentioned as well.
In order to present the concepts of sustainable development to children, these contents ought to be concretised and implemented into the environment of a child's experience with attentive consideration focused upon the specialties of context and the individual's developmental stage on a mental, motivational and social level.

In the majority of architectural communication, the message about the attitude towards the environment is provided mostly by the visual arts, particularly with respect to younger children. For the following work it can be assumed that the selection of element combinations, which children are not capable of integrating into a system by themselves, may express an attitude towards the living culture from the point of view of architecture, even though the visual arts are placed in the second position, at least as far as visualisation, which do not wish to concretise the concept of the cultural development sustainability only through the concretisation of the term "beautiful", and at the same time lose the sense of "culture" are concerned.

The results of the research, if a concrete research is continued are directly useful:

- For assessing the awareness level of children or juveniles regarding "sustainable architecture" topics in Slovenia.

- For determining the qualifications of childcare workers and teachers in conveying a knowledge of the built environment in connection with sustainable development.

Deliberation on the factors to be considered while selecting and developing manners of mediation of architecture contents to children or juveniles, shall be further developed into a classification of levels for each starting point separately (levels of message abstractness, level of awareness ...). This classification will be integrated into a uniform system, which will facilitate decision-making during concrete experiments and assessments of the concrete results in present and future projects.

The results are indirectly also useful for the evaluation for the inclusion of the contents on the built environment and architecture into educational programmes - with the emphasis on Slovene cultural space - or can be used in a process of reforming primary and secondary schools' educational programmes. Last but not the least these efforts lead towards new and other research programmes, towards responsible professional work methods and mostly towards a process of developing a life-long education, with regard to architecture.

Dr. Tadeja Zupančič, Architect, Assistant Professor University of Ljubljana, Faculty of Architecture, Ljubljana, Slovenia E-mail: tadeja.zupancic@fa.uni-lj.si

Dr. Tomaž Novljan, Architect, Assistant Professor University of Ljubljana, Faculty of Architecture, Ljubljana, Slovenia E-mail: tomaz.novljan@fa.uni-lj.si 
Dr. Matevž Juvančič, Architect, Assistant

University of Ljubljana, Faculty of Architecture, Ljubljana, Slovenia E-mail: matevz.juvancic@fa.uni-lj.si

Špela Verovšek, Geographer, Assistant

University of Ljubljana, Faculty of Architecture, Ljubljana, Slovenia

E-mail: spela.verovsek@fa.uni-lj.si

Dr. Maruška Šubic Kovač, Civil Engineer, Associate Professor University of Ljubljana, Faculty of Civil and Geodetic Engineering, Ljubljana, Slovenia

E-mail:msubic@fgg.uni-lj.si

Dr. Andreja Istenič Starčič, Pedagogue, Assistant Professor University of Ljubljana, Faculty of Civil and Geodetic Engineering, Ljubljana, Slovenia

E-mail: andreja.starcic@siol.net

Dr. Matija Svetina, Psychologist, Associate Professor University of Ljubljana, Faculty of Arts, Department of Psychology, Ljubljana, Slovenia

E-mail:m.svetina@ff.uni-lj.si

\section{References}

Bonča, J. (1990) Okolje in zaznava okolja med gibanjem. Master's thesis. Ljubljana, Univerza v Ljubljani, Fakulteta za arhitekturo.

Bosselman, P. (1997) Representation of places - reality and realism in city design. Los Angeles, University of California Press.

Brophy, J., and Good, T. (1986) Teacher behavior and student achievement. In: Wittrock, M. C. (ed.) Handbook of research on teaching. New York, McMillan.

Bromme, R. (1992) Der Lehrer als Experte. Bern, Hans Huber Verlag.

Berliner, D. C. (1988) In pursuit of the expert pedagogue. Educational Researcher, 17, pp. 5-13.

DZS (2002) Slovar slovenskega knjižnega jezika. Ljubljana.

Gray, P. (1999) Psychology. New York, Worth Publishers.

Haberlandt, K. (1994) Cognitive psychology. Boston, Allyn and Bacon.

Hagan, S. (2001) Taking shape: A new contract between architecture and nature. Oxford, Architectural Press.

Ilešič, S. (1979) Pogledi na geografijo. Ljubljana, Partizanska knjiga.

Internet 1: http://europa.eu.int/eurlex/lex/LexUriServ/site/sl/ oj/2005/I_255/I_25520050930sl00220142.pdf (Date accessed 1. 3. 2009).

Internet 2: http://www.rave-space.org/ravespace/homepage.aspx (Date accessed 10. 2. 2009).

Internet 3: http://www.un-documents.net/agenda21.htm (Date accessed 1. 3. 2009).

Internet 4: http://evroterm.gov.si/ (Date accessed 2. 3. 2009).

Internet 5: http://www.mop.gov.si/fileadmin/mop.gov.si/pageuploads/zakonodaja/konvencije/teritorialna_agenda_eu.pdf (Date accessed 1. 3. 2009).
Internet 6: http://www.mop.gov.si/fileadmin/mop.gov.si/pageuploads/zakonodaja/konvencije/leipziska_listina.pdf (Date accessed 1. 3. 2009).

Internet 7: http://eurlex.europa.eu/LexUriServ/LexUriServ.do?uri=C OM:2005:0718:FIN:SL:HTML (Date accessed 1. 3. 2009).

Juvančič, M., and Zupančič, T. (2008) Towards effective interfaces for general architectural learning: eco-spatial aducational interface for pupils. Arhitektura i sovremennye informacionnye tehnologii, 4(5), pp. 1-8.

McDonough, W. (1998) Declaration of Interdependence. In: Scott, A. (ed.) Dimensions of sustainability: Architecture, form, technology, environment, culture, pp. 45-55. London, New York, E\&FN Spon, an imprint of Routledge.

Plut, D. (2002) Teoretični in terminološki vidiki koncepta trajnosti/ sonaravnosti. Geografski vestnik, 74(1), pp. 73-86.

Plut, D. (2007) Sonaravni razvoj (napredek) in geografija. Dela, 28, pp. 287-304.

Rice, F. P. (1998) Human development. Upper Saddle River, Prentice Hall.

Salite, I. (2002) Teachers' views on the aim of education for sustainable development. Journal of teacher education \& training, 2, pp. 68-80.

Schulz, H. O. (1965) Unterricht - Analyse und Planung. Hannover, Schroedel.

Siegler, R., Deloache, J., and Eisenberg, N. (2003) How children develop. New York, Worth Publishers.

Zupančič, T., and Juvančič, M., (2003) Vizualni jezik predstavitve prostora - ovira ali stičišče? Povečevanje učinkovitosti posredovanja idej o prostoru med splošno in strokovno javnostjo [The visual language of spatial presentations - a barrier, or a crossroad? Enhancing the efficiency of communicating spatial ideas to expert and lay publics]. Urbani izziv, 14(2), pp. 35-43 [100-104].

Zupančič, M., and Svetina, M. (2004) Spoznavni razvoj v mladostništvu. In: Marjanovič Umek, L., and Zupančič, M. (eds.) Razvojna psihologija, str. 525-545. Ljubljana, ZIFF. 